Original Research Paper

\title{
Suitability of Egg-laying Habitat and Its Relationship with the Number of Green Turtles (Chelonia mydas) that landed on Pangumbahan Beach Sukabumi
}

\author{
Riska Rismawati $^{1}$, Diana Hernawati ${ }^{1 *}$, Diki Muhamad Chaidir ${ }^{1}$ \\ ${ }^{1}$ Pendidikan Biologi, Fakultas Keguruan dan Ilmu Pendidikan, Universitas Siliwangi, Tasikmalaya, \\ Indonesia;
}

\author{
Article History \\ Received : July $30^{\text {th }}, 2021$ \\ Revised : August $23^{\text {th }}, 2021$ \\ Accepted : September 04 $4^{\text {th }}, 2021$ \\ Published : September $14^{\text {th }}, 2021$ \\ *Corresponding Author: \\ Diana Hernawati, \\ Pendidikan Biologi, Fakultas \\ Keguruan dan Ilmu Pendidikan, \\ Universitas Siliwangi, \\ Tasikmalaya, Indonesia; \\ Email: \\ hernawatibiologi@unsil.ac.id
}

\begin{abstract}
During the nesting season, green turtles have an instinct to return to their original place to lay their eggs. The success of turtle egg laying is influenced by the suitability of the beach for their nesting habitat which consists of physical and biological factors. The purpose of this study was to determine the suitability of the physical and biological factors of green turtle nesting habitat and its relationship to the number of green turtles landed at each station. The research method used is observation, the observation station is determined by purposive sampling, and the data analysis technique used is quantitative. The result is that physical and biological factors consisting of beach width and slope, sand texture and temperature, and vegetation at each landing station on Pangumbahan beach are still suitable as green turtle nesting sites except station 6 . There were 47 green turtles that landed, and station 2 has the highest number of turtles landing, which is 16 turtles. Meanwhile, at station 6, no turtles landed. From the results of the correlation analysis, the beach slope factor and the vegetation density factor have a very strong and significant relationship with the number of turtles that landed. As for the other factors have a fairly - strong relationship. The conclusion is that all factors, both physical and biological factors from the beach, affect the number of green turtles that land, as evidenced by the relationship between the two variables.
\end{abstract}

Keywords: Chelonia mydas; Correlation; Nesting habitat; Pangumbahan beach;

\section{Pendahuluan}

Indonesia memiliki 6 jenis penyu dari 7 jenis penyu yang terdapat di dunia (Juliono \& Ridhwan, 2017). Salah satu penyu yang dapat ditemukan di Indonesia adalah penyu hiau (Chelonia mydas). Penyu hijau hidup di laut tropis dan merupakan jenis penyu yang paling sering ditemukan (Foley et al., 2007; Pradana et al., 2013). Selama masa hidupnya penyu hijau (Chelonia mydas) memerlukan dua habitat yaitu habitat darat dan habitat perairan. Penyu menggunakan habitat darat tepatnya pesisir pantai sebagai tempat untuk bertelur.

Musim bertelur penyu terjadi sepanjang tahun, penyu betina akan menyimpan sperma penyu jantan dalam tubuhnya untuk membuahi tiga sampai tujuh kumpulan telur. Penyu memiliki interval masa peneluran selama 12 sampai 14 hari, dan bertelur sekitar 4 sampai 6 kali setiap tahunnya (Juliono \& Ridhwan, 2017; Kasenda et al., 2013). Habitat pesisir pantai sangat berpengaruh terhadap keberhasilan peneluran penyu hijau. Insting penyu hijau akan memilih pantai dengan kondisi fisik dan biologi habitat yang dirasa sesuai sebagai tempat untuk bertelur.

Penyu hijau memerlukan waktu 25-30 tahun untuk menjadi dewasa (Adnyana \& Hitipeuw, 2009). Penyu hijau memiliki keunikan dalam siklus hidupnya yaitu ketika dewasa dan siap untuk bertelur maka penyu hijau memiliki insting meninggalkan habitat perkembangannya dan kembali ke tempat asal usulnya untuk 
bertelur di kawasan yang sama (Direktorat Konservasi dan Taman Nasioanl Laut, 2009; Foley et al., 2007; Bolten, 2003 dalam Hamabata et al., 2015; Lutz \& Musick, 2013). Selain dipengaruhi oleh insting, keberhasilan penyu bertelur di suatu pantai juga dipengaruhi oleh karakteristik fisik dan biologi pantainya (Mursalin et al., 2017).

Pantai Pangumbahan merupakan salah satu tempat yang dijadikan indeks lokasi pengamatan kondisi populasi penyu hijau (IUCN 2004 dalam Hartono et al., 2012). Kawasan konservasinya memiliki luas 58,43 Ha dengan panjang pantai habitat peneluran penyu (nesting ground) $\pm 2.300 \mathrm{~m}$, terbagi menjadi enam stasiun pendaratan dengan luas masing-masing staisun 300-400 meter (Pane et al., 2020). Pantai Pangumbahan berhadapan langsung dengan Samudera Hindia dan memiliki kondisi fisik pantai yang sesuai dan mendukung bagi peneluran penyu hijau.

Pendaratan dan peneluran penyu hijau dipengaruhi oleh banyak faktor termasuk kesesuaian pantai pendaratan (Budiantoro, 2017). Penyu hijau (Chelonia mydas) bertelur pada tipe pantai yang mudah dicapai dari laut namun tidak sampai membuat sarang terendam oleh air pasang tertinggi, pasirnya berukuran sedang agar tidak runtuh saat menggali sarang, kelembaban yang cukup dan suhu antara $25^{\circ} \mathrm{C}-$ $32^{\circ} \mathrm{C}$ (Dharmadi \& Wiadnyana, 2017; Suwelo et al., 1985 dalam Pradana et al., 2013).

Faktor fisik pantai yang memengaruhi keberhasilan pendaratan dan peneluran penyu hijau diantaranya panjang dan lebar pantai, kemiringan pantai, tekstur pasir, suhu pasir, dan kelembaban pasir. Sedangkan, untuk faktor biologinya adalah vegetasi pantai dan juga predator. Tujuan dari penelitian ini adalah untuk mengetahui karakteristik fisik dan biologi pantai Pangumbahan sebagai tempat pendaratan penyu hijau dan hubungannya dengan jumlah penyu hijau yang mendarat di setiap stasiun di pantai Pangumbahan.

\section{Bahan dan Metode}

\section{Waktu dan Tempat Penelitian}

Penelitian dilaksanakan selama satu bulan yaitu pada bulan Maret 2021. Penelitian dilaksanakan di Taman Pesisir Penyu Pantai Pangumbahan Kabupaten Sukabumi yang merupakan salah satu tempat konservasi penyu hijau (Chelonia mydas) di Indonesia.

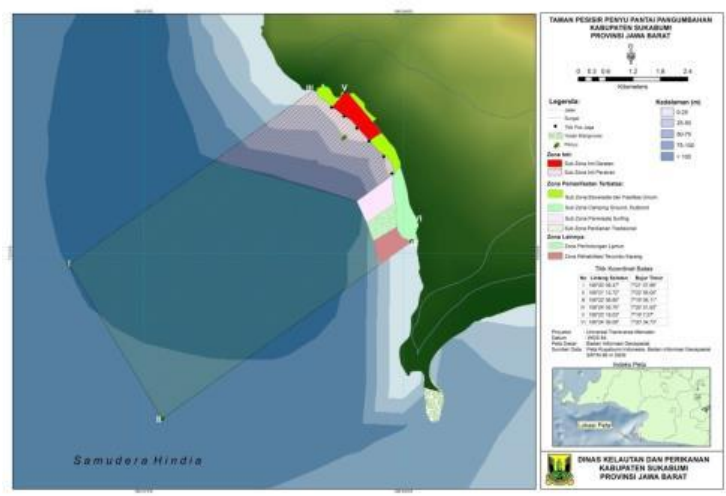

Gambar 1. Peta Kawasan Konservasi Penyu Hijau Pantai Pangumbahan

Sumber: Dinas Kelautan dan perikanan Kabupaten Sukabumi

\section{Metode Penelitian}

Penelitian ini menggunakan metode observasi, dengan penentuan stasiun pengamatan secara purposive sampling. Terdapat enam stasiun yang digunakan dalam penelitian ini berdasarkan jumlah stasiun yang sudah lama ditetapkan oleh petugas pengelola konservasi Pantai Pangumbahan, dan setiap stasiun dibatasi oleh patok. Sedangkan, penentuan titik pengambilan data faktor fisik dan biologi pantai dari setiap stasiun, ditentukan berdasarkan titik yang dimana terdapat sarang penyu hijau terbaru di setiap stasiunnya. Data yang diambil yaitu faktor fisik dan biologi pantai diantaranya lebar pantai, kemiringan pantai, tekstur pasir, suhu dan kelembaban pasir, vegetasi dan jumlah penyu hijau yang mendarat selama satu bulan di setiap stasiunnya. Alat yang digunakan adalah soilmeter, sieve shaker, roll meter, tali raffia, dan alat tulis.

\section{Pengambilan Data \\ Pengukuran Lebar Pantai}

Lebar pantai yang diukur adalah lebar keseluruhan yaitu gabungan antara lebar supratidal (daerah pantai yang tidak terkena air pada saat pasang) dengan lebar intertidal (daerah antara batas pasang tertinggi dengan batas surut terendah). 


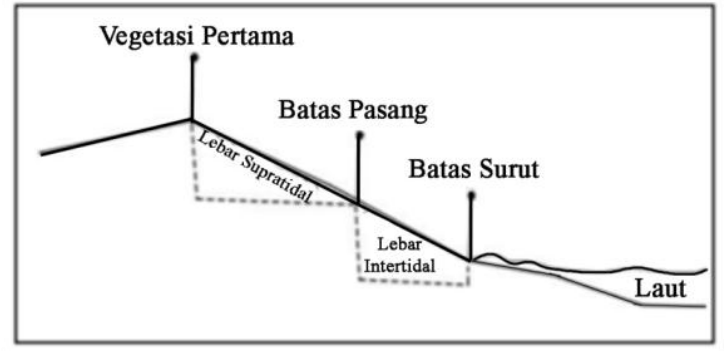

Gambar 2. Sketsa lebar pantai yang diukur

\section{Pengukuran Kemiringan Pantai}

Pengukuran diambil tegak lurus dari batas vegetasi terakhir pantai sampai batas pantai yang pertamakali basah oleh gelombang air laut. Kemiringan pantai diukur menggunakan roll meter, tongkat kayu berukuran $2 \mathrm{~m}$, dan waterpass untuk mempertahankan kelurusan (Anshary et al., 2014).

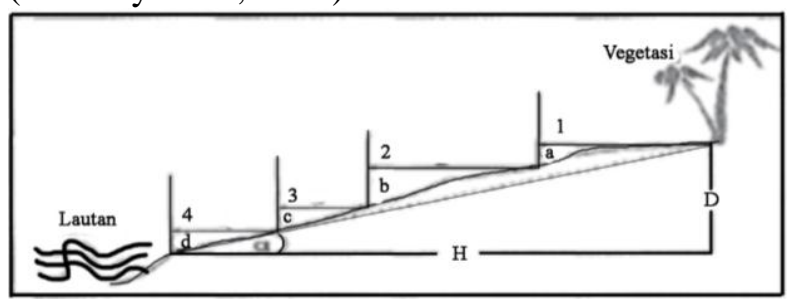

Gambar 3. Sketsa Pengukuran Kemiringan Pantai

Analisis Kemiringan Pantai menggunakan rumus dari Anshary et al (2014):

$$
\operatorname{tg} a=(1+2+3+4) /(a+b+c+d)
$$

Keterangan:

Tga = sudut kemiringan pantai (o)

$\mathrm{H} \quad=$ jarak total dari pantai $(\mathrm{m})$

$\mathrm{D} \quad=$ Tinggi total pantai $(\mathrm{m})$

\section{Pengukuran Tekstur pasir}

Ukuran pasir diukur menggunakan saringan bertingkat (seiving) kemudian ditimbang berdasarkan ukuran butiran substrat dari Skala Wentworth (Setiawan et al., 2018). Sampel yang digunakan adalah pasir pantai yang diambil dari setiap stasiun pendaratan masingmasing sebanyak 400 gram.

\section{Pengukuran Suhu dan Kelembaban Pasir}

Suhu dan kelembaban diukur menggunakan soil meter 4 in 1 dengan cara menancapkan soilmeter pada kedalaman $60 \mathrm{~cm}$ pada pasir pantai dis etiap stasiun. Diukur setiap pagi, siang dan malam kemudian diambil rataratanya.

\section{Pengukuran Vegetasi Pantai}

Pengambilan data vegetasi dilakukan dengan menggunakan metode petak kuadrat di setiap stasiun pengamatan dengan ukuran plot 10x10 meter dengan petak $1 \times 1$ meter.

\section{Identifikasi Jumlah Penyu yang Bersarang}

Untuk mengetahui jumlah penyu hijau yang bersarang di setiap stasiunnya maka dilakukan pengamatan langsung di lapangan bersama dengan petugas penjaga stasiun pendaratan kemudian mencatatnya selama satu bulan.

\section{Analisis Data}

Untuk mengetahui nilai kerapatan vegetasi (K) maka menggunakan rumus (Nelawati et al., 2020):

$$
\mathrm{K}=\frac{\text { Jumlah individu suatu jenis }(\mathrm{N})}{\text { Luas petak contoh }}
$$

Untuk mengatahui hubungan antara setiap faktor dengan jumlah penyu hijau yang bersarang dilakukan analisis korelasi bivariat anatara kemiringan pantai dengan jumlah penyu hijau yang bersarang disetiap stasiunnya menggunakan aplikasi SPSS statistics versi 26.

\section{Hasil dan Pembahasan}

\section{Faktor Fisik dan Biologi Pantai}

Hasil pengamatan faktor-faktor yang dapat memengaruhi keberhasilan mendarat dan bertelur penyu hijau yaitu lebar antai Pangumbahan berkisar antara $17 \mathrm{~m}-45 \mathrm{~m}$ untuk lebar supratidal dan $15 \mathrm{~m}-28 \mathrm{~m}$ untuk lebar intertidal.

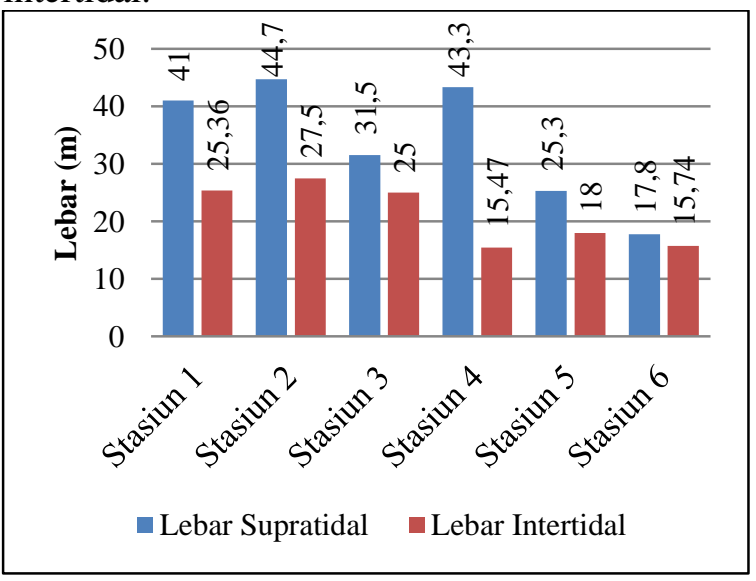

Gambar 4. Lebar pantai Pangumbahan 
Kemiringan setiap stasiun habitat pendaratan penyu hijau berkisar antara $5,76^{\circ}$ $20,16^{\circ}$. Ukuran pasir paling halus terdapat pada stasiun 6 dengan nilai 1,05 dan paling kasar terdapat pada stasiun 1 dengan nilai 1,79. Namun keduanya masih termasuk kedalam pasir halus. Rata-rata suhu pantai yang diukur pada pagi, siang dan malam berkisar antara $29^{\circ} \mathrm{C}-30{ }^{\circ} \mathrm{C}$. Kelembaban pasir diukur dengan soil meter bernilai 1 yaitu termasuk kategori kering (Dry). Sedangkan untuk kerapatan vegetasi (K) paling tinggi terdapat di stasiun 3 dengan nilai 1,47 dan paling rendah di stasiun 6 dengan nilai 0,33 . Data yang lebih jelas dari setiap faktor, dapat dilihat pada tabel 1 .

Tabel 1. Faktor fisik dan biologi setiap stasiun pendaratan

\begin{tabular}{lcccccc}
\hline \multirow{2}{*}{ Faktor } & \multicolumn{7}{c}{ Stasiun Pendaratan } \\
\cline { 2 - 7 } & $\mathbf{1}$ & $\mathbf{2}$ & $\mathbf{3}$ & $\mathbf{4}$ & $\mathbf{5}$ & $\mathbf{6}$ \\
\hline Lebar Pantai $(\mathrm{m})$ & 66,36 & 72,20 & 56,50 & 58,47 & 41,50 & 33,54 \\
\hline Kemiringan Pantai $(\mathrm{m})$ & 9,72 & 5,76 & 10,08 & 9,36 & 12,24 & 20,16 \\
\hline Tekstur Pasir & 1,79 & 1,28 & 1,33 & 1,37 & 1,36 & 1,05 \\
\hline Suhu Pasir $\left({ }^{\circ} \mathrm{C}\right)$ & 29 & 29 & 30 & 30 & 30 & 30 \\
\hline Kelembaban Pasir & 1 & 1 & 1 & 1 & 1 & 1 \\
\hline Kerapatan vegetasi & 0,44 & 0,85 & 1,47 & 0,40 & 0,73 & 0,33 \\
\hline
\end{tabular}

Jumlah Penyu Hijau (Chelonia mydas) yang Bersarang

Penyu hijau yang mendarat tidak selalu bertelur, ada yang mendarat hanya untuk memilih terlebih dahulu lokasi bertelurnya. Namun dalam penelitian ini, data yang diambil adalah seluruh penyu hijau yang mendarat baik yang bertelur maupun tidak bertelur. Berdasarkan hasil pengamatan lapangan selama satu bulan, jumlah penyu hijau yang mendarat yaitu sebanyak 47, data lengkap jumlah penyu hijau yang mendarat setiap stasiunnya dapat dilihat pada gambar 4 .

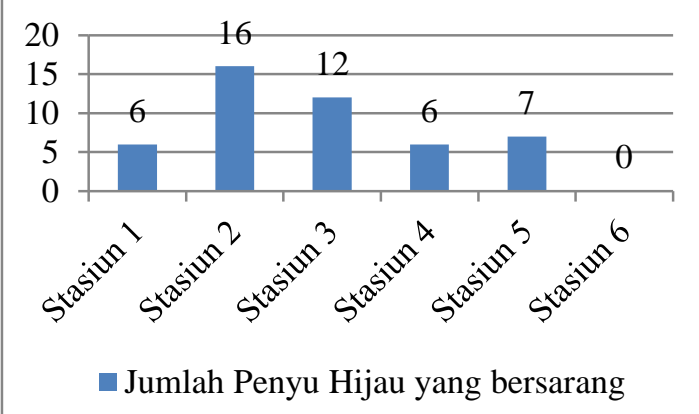

Gambar 5. Jumlah Penyu Hijau yang Mendarat Setiap Stasiun

\section{Lebar Pantai}

Nilai lebar pantai sangat memengaruhi daya aksesibilitas penyu dalam mencapai lokasi pembuatan sarang. Lebar pantai yang disukai penyu berada pada kisaran 30 - 80 meter (Atuany et al., 2020). Penyu hijau akan memilih pantai yang lebar agar gelombang air laut tidak dapat mencapai sarang telur penyu hijau. Berdasarkan tabel 1, lebar pantai Pangumbahan sangat sesuai sebagai tempat bertelur penyu karena berada pada kisaran 30-80 meter. Kemudian berdasarkan gambar 3, setiap stasiun memiliki lebar supratidal yang lebih besar hal ini sangat baik karena zona supratidal merupakan zona yang aman dari gelombang air laut. Stasiun 6 memiliki nilai lebar yang paling kecil karena pantainya tidak begitu landai.

\section{Kemiringan Pantai}

Kemiringan pantai merupakan salah satu faktor fisik pantai yang memengaruhi keberhasilan pendaratan penyu hijau. Nuitja (1992) menyatakan bahwa pantai yang sesuai sebagai tempat mendarat penyu hijau adalah pantai yang landai dengan kemiringan dengan rata-rata $30^{\circ}$ (Pratama \& Romadhon, 2020; Putra et al., 2014; Siahaan et al., 2020). Berdasarkan hasil penelitian, stasiun yang paling rendah nilai kemiringannya adalah stasiun 2 dengan derajat kemiringan $5,76^{\circ}$. Untuk nilai kemiringan tertinggi ada pada stasiun 6 dengan derajat kemiringan 20,16 ${ }^{\circ}$. Stasiun 6 merupakan stasiun pendaratan penyu yang paling curam diantara stasiun yang ada di pantai Pangumbahan sehingga menyulitkan penyu naik mencapai vegetasi untuk bertelur. Untuk stasiun lain sudut kemiringannya tidak terlalu berbeda jauh, dan 
merupakan pantai landai. Meskipun begitu, semua stasiun pendaratan yang ada di pangumbahan nilai kemiringannya kurang dari $30^{\circ}$ yang menjadi patokan rata-rata kemiringan pantai yang sesuai.

Penyu hijau lebih menyukai pantai yang landai karena sama halnya dengan lebar pantai yaitu berhubungan dengan aksesibilitas penyu untuk mencapai tempat membuat sarang. Semakin tinggi nilai kemiringan pantai, maka energi yang diperlukan penyu untuk mencapai lokasi bertelur akan semakin besar (Langinan et al., 2017). Namun lokasi pantai dengan kemiringan tertentu juga dibutuhkan penyu agar gelombang air laut tidak sampai ke sarang. Selain stasiun 6, semua stasiun termasuk kedalam kategori pantai yang landai. Meskipun pantai yang landai disukai penyu hijau dalam memilih tempat untuk membuat sarang, namun pantai yang landai tidak cocok dijadikan tempat pertumbuhan telur penyu sampai menetas karena pesisirnya dapat terendam air laut saat pasang atau saat ada gelombang yang tinggi. Untuk itu, di Pantai Pangumbahan, setiap telur dari sarang alami akan dipindahkan ke sarang semi alami agar telur tidak menerima banyak gangguan sampai akhirnya berhasil menetas.

Apabila pantai memiliki kemiringan yang terlalu curam maka akan mengganggu kemampuan penyu hijau untuk melihat objek. Kemampuan akomodasi penyu agar dapat melihat dengan baik adalah pada sudut $150^{\circ}$ kebawah (Kurniawan et al., 2020). Hasil pengukuran kelandaian pantai tidak sama pada setiap stasiunnya hal ini disebabkan arus yang berubah-ubah dan adanya abrasi, sedangkan perbedaan kemiringan pantai terjadi karena adanya akumulasi penumpukan pasir akibat angin dan ombak saat terjadi pasang (Yuriadi, 2000 dalam Siahaan et al., 2020). Kondisi pantai Pangumbahan juga dipengaruhi oleh pasang surut air laut. Kemiringan pantai memiliki kaitan yang erat dengan lebar pantai, semakin landai pantai maka semakin tinggi pula nilai intertidalnya. Jadi apabila dilakukan pengukuran pada dua musim berbeda (musim hujan dan musim kemarau) maka hasilnya akan berbeda.

\section{Tekstur Pasir}

Ukuran pasir yang disukai penyu hijau adalah pasir yang halus, karena pasir kasar (berukuran besar) akan memperbesar gaya gesek saat penyu menggali sarang sehingga energi yang dikeluarkan penyu juga harus lebih besar (Sasaerila et al., 2017). Ukuran pasir yang terlalu halus juga tidak baik dan tidak disukai penyu karena pasir yang terlalu halus akan membuat sarang mudah longsor. Berdasarkan tabel 1, ukuran pasir di Pantai Pangumbahan sudah sesuai karena termasuk kategori halus, tidak kasar namun tidak terlalu halus.

\section{Suhu dan Kelembaban Pasir}

Kisaran suhu yang memberikan toleransi kepada embrio dari telur penyu untuk dapat berkembang sampai menetas menjadi tukik adalah antara $24-33^{\circ} \mathrm{C}$ (Parinding, 2021). Setiap stasiun di Pantai Pangumbahan memiliki kisaran suhu pasir yang sesuai bagi perkembangan embrio penyu hijau. Namun, suhu pasir juga sangat dipengaruhi oleh cuaca jadi suhu tidak akan selalu konstan pada kisaran yang sesuai. Dalam penelitian ini, kondisi cuaca saat pengambilan data suhu adalah cerah (tidak terjadi hujan).

Suhu pasir yang diukur di Pantai Pangumbahan rata-rata antara $29^{\circ} \mathrm{C}-30^{\circ} \mathrm{C}$. Suhu pasir yang tetap pada angka tertentu tidak baik karena akan memengaruhi jenis kelamin tukik. Apabila tukik yang dihasilkan hanya satu jenis maka akan berpengaruh negative terhadap keberlangsungan populasi penyu hijau itu sendiri. Jenis kelamin tukik yang dihasilkan pada penyu hijau dipengaruhi oleh suhu sarang saat inkubasi. Apabila suhu antara $28-29^{\circ} \mathrm{C}$ maka penyu yang dihasilkan kemungkinan besar jantan sedangkan apabila suhu $30-31^{\circ} \mathrm{C}$ maka penyu yang dihasilkan kemungkinan besar betina (Akbar et al., 2020).

Kelembaban pasir bernilai 1, berarti pasir termasuk kategori kering. Kelembaban menunjang keberhasilan perkembangan embrio penyu hijau. Kelembaban tidak boleh terlalu tinggi ataupun terlalu rendah. Kelembaban yang tinggi akan meningkatkan potensi mikroorganisme untuk berkembang dan akan merusak embrio. Jika kelembaban rendah maka telur yang diinkubasi akan kekeringan dan menyebabkan telur gagal menetas (Kurniawan et al., 2020).

\section{Kerapatan Vegetasi}

Vegetasi merupakan hal yang sangat penting dalam penentuan keberhasilan penyu 
hijau mendarat. Nilai kerapatan vegetasi yang tinggi akan membuat hutan pantai terlihat rimbun dan akan menarik penyu hijau saat memilih tempat bertelur. Vegetasi yang rimbun akan memberikan rasa aman ketika penyu bertelur (Bara et al., 2013; Ridwan et al., 2017). Selain itu, vegetasi yang ada disekitar tempat peneluran akan memberikan kestabilan pada pasir saat penggalian sarang (Dharmadi \& Wiadnyana, 2008; Juliono \& Ridhwan, 2017; Sheavtiyan et al., 2014). Sedangkan vegetasi yang rusak akan menyebabkan pantai erosi dan membuat tumbuhan menjalar banyak tumbuh sehingga akan menyulitkan penyu alam menggali sarang (Dharmadi \& Wiadnyana, 2008).

\section{Analisis Korelasi}

Analisis korelasi antara setiap faktor dengan jumlah penyu hijau yang mendarat didapatkan hasil seperti pada tabel 2. Hubungan kemiringan pantai dengan jumlah penyu mendarat dianalisis menggunakan analisis korelasi pearson, sedangkan untuk faktor lainnya menggunakan analisis korelasi Spearman rank.

Tabel 2. Hasil Analisis Korelasi

\begin{tabular}{|c|c|c|c|}
\hline & & & $\begin{array}{c}\text { Jumlah penyu } \\
\text { Mendarat }\end{array}$ \\
\hline \multirow[t]{3}{*}{ Pearson } & \multirow[t]{3}{*}{ Kemiringan } & Pearson Correlation & $-0.850^{*}$ \\
\hline & & Sig. (2-tailed) & 0.032 \\
\hline & & $\mathrm{N}$ & 6 \\
\hline \multirow{12}{*}{ Spearman's rho } & \multirow[t]{3}{*}{ Lebar } & Correlation Coefficient & 0.522 \\
\hline & & Sig. (2-tailed) & 0.288 \\
\hline & & $\mathrm{N}$ & 6 \\
\hline & \multirow[t]{3}{*}{ Suhu } & Correlation Coefficient & -0.522 \\
\hline & & Sig. (2-tailed) & 0.288 \\
\hline & & $\mathrm{N}$ & 6 \\
\hline & \multirow[t]{3}{*}{ Tekstur } & Correlation Coefficient & -0.315 \\
\hline & & Sig. (2-tailed) & 0.543 \\
\hline & & $\mathrm{N}$ & 6 \\
\hline & \multirow{3}{*}{$\begin{array}{l}\text { Kerapatan } \\
\text { Vegetasi }\end{array}$} & Correlation Coefficient & $0.928^{* *}$ \\
\hline & & Sig. (2-tailed) & 0.008 \\
\hline & & $\mathrm{N}$ & 6 \\
\hline
\end{tabular}

*. Correlation is significant at the 0.05 level (2-tailed).

**. Correlation is significant at the 0.01 level (2-tailed).

Berdasarkan tabel 2, faktor yang memiliki korelasi yang sangat kuat dan signifikan dengan jumlah penyu hijau yang mendarat adalah kemiringan pantai dan kerapatan vegetasi. Selain itu, faktor yang lain memiliki hubungan antara cukup - kuat namun tidak signifikan. Dari hasil analisis korelasi, nilai koefisien korelasi antara kerapatan vegetasi dengan jumlah penyu hijau yang mendarat adalah $0,928^{* *}$, berarti kedua variabel memiliki hubungan yang sangat kuat. Koefisien bernilai positif berarti hubungan kedua variabel searah, yaitu apabila nilai kerapatan meningkat, maka jumlah penyu hijau yang mendarat juga akan meningkat, dan sebaliknya apabila nilai kerapatan menurun maka julah penyu hijau yang mendarat juga akan menurun. Kemudian berdasarkan nilai Sig. (2-tailed) yaitu terdapat hubungan yang signifikan antara kedua variabel karena nilai Sig. (2-tailed) 0,008 > dari
0,01 .

Nilai kerapatan tertinggi terdapat di stasiun 3 dan stasiun 2, sedangkan stasiun 6 memiliki nilai kerapatan paling rendah. Semakin rapat vegetasi maka hutan pantai akan semakin rimbun dan kemungkinan besar akan lebih menarik penyu hijau untuk mendarat dan bertelur. Hal ini memang terbukti dengan banyaknya penyu yang mendarat di staisun 2 dan stasiun 3, dan sebaliknya di stasiun 6 tidak terdapat penyu yang mendarat.

Hasil analisis korelasi antara kemiringan pantai dengan jumlah penyu hijau yang mendarat (Pearson Corelation / r) adalah 0,850. Karena r $>\mathrm{t}$ tabel maka hal ini menunjukan adanya hubungan atau korelasi yang kuat antara kemiringan pantai dengan jumlah penyu yang mendarat. Kemudian karena $r$ hitung atau pearson correlation bernilai negatif artinya 
hubungan kedua variable bersifat negatif/berlawanan yaitu semakin meningkat nilai kemiringan maka semakin rendah jumlah penyu hijau yang mendarat dan sebaliknya. Kemudian nilai Sig. (2-tailed) adalah sebesar 0,032. Karena Sig. (2-tailed) $<0,05$ artinya terdapat korelasi antara kedua variabel.

Penyu hijau paling banyak mendarat di stasiun 2 yang merupakan pantai yang landai, sedangkan di stasiun 6 yang memiliki pantai dengan nilai kemiringan paling tinggi, tidak terdapat penyu hijau yang mendarat.Meskipun di stasiun 6 nilai kemiringannya masih jauh ke nilai rata-rata, tetap saja dengan nilai $20,16^{\circ}$ di pantai Pangumbahan sudah termasuk curam dan berbeda jauh dengan nilai kemiringan stasiun lain.

Adanya korelasi antara kemiringan pantai dengan jumlah penyu hijau yang mendarat selaras dengan teori dari Nuitja (1992). Apabila pantai curam maka akan menyulitkan akomodasi mata penyu (Wicaksono et al., 2013). Sebaliknya, apabila pantai landai maka akan mempermudah penyu untuk sampai ke vegetasi saat akan bertelur, sehingga tenaga atau energi yang dikeluarkan penyu saat naik tidak terlalu besar (Setiawan et al., 2018). Stasiun 2 merupakan stasiun paling landai sehingga penyu hijau paling banyak mendarat.

Faktor fisik lainnya yaitu lebar pantai dan suhu pasir, yang memiliki nilai koefisien korelasi sebesar 0,522 dan -0,522. Artinya lebar pantai dan suhu pasir merupakan faktor yang berhubungan kuat dengan jumlah penyu hijau yang mendarat. Nilai signifikansinya yaitu 0,288 yang berarti hubungan kedua variabel, baik antara lebar pantai dengan jumlah penyu yang mendarat ataupun suhu pasir dengan jumlah penyu yang mendarat sama-sama tidak signifikan. Lebar pantai memiliki kisaran tertentu agar cocok sebagai tempat mendarat penyu hijau, sehingga nilainya tidak boleh terlalu tinggi atau terlalu rendah. Nilai koefisien korelasi suhu adalah negatif, berarti arahnya berlawanan dengan jumlah penyu hijau yang mendarat. Penyu memang selalu bertelur pada malam hari saat suhu rendah (Pradana et al., 2013). Suhu memang tidak berpengaruh langsung terhadap induk penyu yang mendarat, tetapi suhu sangat memengaruhi keberhasilan perkembangan telur penyu sampai menetas.
Faktor selanjutnya adalah tekstur pasir yang memiliki nilai koefisien korelasi sebesar 0,315 yang berarti memiliki hubungan yang cukup kuat dengan jumlah penyu hijau yang mendarat. Berdasarkan nilai signifikansinya, maka hubungan antara kedua variabel ini tidak signifikan. Nilai koefisiennya adalah negative, berarti apabila nilai tekstur pasir tinggi maka jumlah penyu hijau yang mendarat akan menurun.Tekstur pasir memang salah satu faktor yang dipertimbangkan penyu hijau dalam memilih tempat untuk bertelur. Namun hubungannya dengan jumlah penyu hijau yang mendarat tidak signifikan karena pasir pantai Pangumbahan di setiap stasiunnya termasuk kedalam kategori halus dan nilai teksturnya tidak berbeda jauh antara stasiun satu dengan stasiun yang lain berarti tekstur pasir sudah sesuai.

Lebar pantai, kemiringan pantai, tekstur substrat, suhu pasir dan vegetasi merupakan faktor yang berpengaruh dan memiliki hubungan dengan keberhasilan pendaratan penyu hijau, meskipun nilai korelasinya ada yang kuat dan ada yang cukup. Selain itu, curah hujan atau cuaca merupakan faktor lain yang juga berpengaruh pada keberhasilan pendaratan penyu (Wicaksono et al., 2013), predator (Siahaan et al., 2020), dan aktivitas-aktivitas di sekitar pantai pendaratan karena penyu hijau cenderung menyukai suasana yang sepi (Mansula \& Romadhon, 2020).

\section{Kesimpulan}

Berdasarkan hasil penelitian, dapat disimpulkan bahwa pantai pangumbahan masih sesuai sebagai tempat mendarat dan bertelur penyu hijau dilihat dari fator fisik dan biologinya yang selaras dengan teori-teori dan dilihat dari masih banyaknya penyu hijau yang mendarat di pantai Pangumbahan. Kemudian ketika dihubungkan, terdapat dua faktor yaitu kemiringan pantai dan kerapatan vegetasi pantai yang memiliki hubugan yang sangat kuat sekaligus signifikan dengan jumlah penyu hijau yang mendarat selama bulan Maret 2021. Penyu cenderung mendarat pada panyai dengan nilai kemiringan yang rendah dan pantai dengan nlai kerapatan vegetasi yang tinggi. Sedangkan untuk faktor-faktor lain juga tetap memiliki hubungan meskipun kategorinya bukan sangat kuat. 


\section{Referensi}

Adnyana, I. W., \& Hitipeuw, C. (2009). Panduan Melakukan Pemantauan Populasi Penyu di Pantai Peneluran di Indonesia. World Wide Fund fot Nature (WWF) \& Universitas Udayana.

Akbar, M. R., Luthfi, O. M., \& Barmawi, M. (2020). Kesesuaian Lahan Peneluran Penyu Lekang Lepidochelys olivacea, Eschscholtz, 1829 (Reptilia: Cheloniidae) di Pantai Mapak Indah, Nusa Tenggara Barat. Journal Of Marine Research, 9(2), 137-142.

Anshary, M., Setyawati, Tri rima \& Yanti, Ari hepi (2014). Karakteristik Pendaratan Penyu Hijau ( Chelonia mydas , Linnaeus 1758 ) di Pesisir Pantai Tanjung Kemuning Tanjung Api dan Pantai Belacan Kecamatan Paloh Kabupaten Sambas. Jurnal Protobiont, 3(2), 232-239.

Atuany, D. J., Hitipeuw, J. C., \& Tuhumury, A. (2020). Karakteristik Area Tempat Bertelur Penyu Sisik (Eretmochelys imbricata) Pantai Faong Taman Nasional Manusela. MAKILA:Jurnal Penelitian Kehutanan Volume, 14(2), 135-146. https://doi.org/10.30598/makila.v14i2.289 3

Bara, D. A., Redjeki, S., \& Hariadi. (2013). Studi Habitat Peneluran Penyu Hijau (Chelonia mydas) di Pantai Pangumbahan, Sukabumi Jawa Barat. Journal of Marine Rese, 2, 127-133.

Budiantoro, A. (2017). Zonasi Pantai Pendaratan Penyu di Sepanjang Pantai Bantul. Jurnal Riset Daerah, 1-21.

Dharmadi, \& Wiadnyana, N. N. (2008). Kondisi Habitat dan Kaitannya dengan Jumlah Penyu Hijau (Chelonia mydas) yang Bersarang di Pulau Derawan, BerauKalimantan Timur. Jurnal Penelitian Perikanan Indonesia, 14(2), 195-204. https://doi.org/10.15578/jppi.14.2.2008.19 5-204
Direktorat Konservasi dan Taman Nasioanl Laut (2009). Pedoman Teknis Pengelolaan Konservasi Penyu. Direktorat Konservasi dan Taman Nasional Laut, Direktorat Jenderal Kelautan, Pesisir dan Pulau-Pulau Kecil, Departemen Kelautan dan Perikanan RI.

Foley, A. M., Singel, K. E., Dutton, P. H., Summers, T. M., Redlow, A. E., \& Lessman, J. (2007). Characteristics of a green turtle (Chelonia mydas) assemblage in northwestern Florida determined during a hypothermic stunning event. Gulf of Mexico Science, 25(2), 131-143. https://doi.org/10.18785/goms.2502.04

Hamabata, T., Hikida, T., Okamoto, K., Watanabe, S., \& Kamezaki, N. (2015). Ontogenetic habitat shifts of green turtles (Chelonia mydas) suggested by the size modality in foraging aggregations along the coasts of the western Japanese main islands. Journal of Experimental Marine Biology and Ecology, 463, 181-188. https://doi.org/10.1016/j.jembe.2014.12.00 7

Hartono, T. T., Kartodihardjo, H., Purbayanto, A., \& Satria, A. (2012). Rezim Hak Kepemilikan Dan Akses Terhadap Sumberdaya Lahan Bagi Efektivitas Institusi Pengelolaan Kawasan Konservasi Penyu. Jurnal Sosial Ekonomi Kelautan Dan Perikanan, $7(2), \quad 165$. https://doi.org/10.15578/jsekp.v7i2.5683

Juliono, \& Ridhwan, M. (2017). Penyu dan Usaha Pelestariannya. Serambi Saintia, 5(1), 45-54.

Kasenda, P., Boneka, F. B., \& Wagey, B. T. (2013). Lokasi Bertelur Penyu di Pantai Timur Kabupaten Minahasa Provinsi Sulawesi Utara. Jurnal Pesisir Dan Laut Tropis, 2(1), 58-62.

Kurniawan, W., Erianto, \& Dewantara, I. (2020). Jumlah Tempat Peneluran Penyu Hijau (Chelonia Mydas) Berdasarkan Vegetasi Pantai Di Taman Wisata Alam (Twa) Tanjung Belimbing Kecamatan Paloh 
Kabupaten Sambas. Jurnal Hutan Lestari, 8(3), 605-619.

Langinan, F., Boneka, F. B., \& Wagey, B. T. (2017). Aspek Lingkungan Lokasi Bertelur Penyu Di Pantai Taturian, Batumbalango Talaud. Jurnal Pesisir Dan Laut Tropis, 1(2), 26-31.

Lutz, P. L., \& Musick, J. A. (2013). The Biology of Sea Turtles. In P. L. Lutz \& J. A. Musick (Eds.), CRC Marine Science Series. CRC Press.

Mansula, J. G., \& Romadhon, A. (2020). Analisis Kesesuaian Habitat Peneluran Penyu di Pantai Saba. Juvenil, 1(1), 8-18.

Mursalin, Budhi, S., \& Manurung, T. F. (2017). Karakteristik Lokasi Peneluran Penyu Hubungannya Dengan Struktur Dan Komposisi Vegetasi Di Pantai Sebubus Kecamatan Paloh Kabupaten Sambas. Jurnal Hutan Lestari, 5(2), 338-347.

Nelawati, Anggraeni, \& Akhrianti, I. (2020). Analisis struktur vegetasi kawasan sempadan pantai di kabupaten bangka tengah. Ekotonia: Jurnal Penelitian Biologi, Botani, Zoologi Dan Mikrobiologi, 05(1), 9-16.

Pane, E. P., Muhamad, I. N., \& Wiadnya, D. (2020). P Engelolaan K Onservasi : S Tudi $\mathrm{K}$ Asus K Onservasi P Enyu. Prosiding Seminar Nasional Perikanan Dan Kelautan VII, 126-130.

Parinding, Z. (2021). Preferensi Habitat Persarangan Penyu Di Kawasan Pulau Kecil. CENDEKIA : Jurnal Ilmu Pengetahuan, 1(2), 8-14.

Pradana, F. A., Syafruddin Said, \& Sarma Siahaan. (2013). Habitat Tempat Bertelur Penyu Hijau (Chelonia mydas) di Kawasan Taman Wisata Alam Sungai Liku Kabupaten Sambas Kalimantan Barat. Jurnal Hutan, 1(2), 156-163.

Pratama, A. A., \& Romadhon, A. (2020). Karakteristik Habitat Peneluran Penyu Di
Pantai Taman Kili-Kili Kabupaten Trenggalek Dan Pantai Taman Hadiwarno Kabupaten Pacitan. Juvenil:Jurnal Ilmiah Kelautan Dan Perikanan, 1(2), 198-209. https://doi.org/10.21107/juvenil.v1i2.7574

Putra, B. A., K, E. W., \& Rejeki, S. (2014). Studi Karakteristik Biofisik Habitat Peneluran Penyu Hijau (Chelonia mydas) di Pantai Paloh, Sambas, Kalimantan Barat. Diponegoro Journal of Marine Research, $3(3)$, 173-181. https://doi.org/10.14710/jmr.v3i3.5988

Ridwan, exfar alli, Sara, L., \& Asriyana. (2017). Karakteristik biofisik habitat peneluran Penyu Hijau (Chelonia mydas) di Pantai Kampa, Konawe Kepulauan. Jurnal Manajemen Sumber Daya Perairan, 2(4), 295-305.

Sasaerila, Y., Elfidasari, D., \& Sabil, M. Q. T. (2017). Struktur Vegetasi dan Karakteristik Habitat Peneluran Penyu Hijau (Chelonia mydas) di Kawasan Konservasi Penyu Pangumbahan Sukabumi. Jurnal Al-Azhar Indonesia Seri Sains Dan Teknologi, 4(1), 36-43. https://doi.org/10.36722/sst.v4i1.249

Setiawan, R., Zamdial, \& Fajar SPN, B. (2018). Study of the characteristic of sea turtle nesting area in Pekik Nyaring Village, Pondok Kelapa District, Central Bengkulu Regency, Bengkulu Province. Jurnal Ilmu Kelautan Kepulauan, 1(1), 59-70.

Sheavtiyan, Setyawati, T. R., \& Lovadi1, I. (2014). Tingkat Keberhasilan Penetasan Telur Penyu Hijau (Chelonia Mydas, Linnaeus 1758) di Pantai Sebubus, Kabupaten Sambas Sheavtiyan1,. Jurnal Protobiont, 3(1), 46-54.

Siahaan, V. O., Thamrin, \& Tanjung, A. (2020). Habitat Characteristics Nesting Environment of Green Turtle ( Chelonia mydas ) Pandan Island of West Sumatera. $1(1), 1-6$.

Wicaksono, M. A., Elfidasari, D., \& Kurniawan, A. (2013). Aktivitas Pelestarian Penyu 
Rismawati, et al. (2021). Jurnal Biologi Tropis, 21 (3): 681 - 690 DOI: http://dx.doi.org/10.29303/jbt.v21i3.2844

Hijau ( Chelonia mydas ) di Taman Pesisir Pantai Penyu Pangumbahan Sukabumi Jawa Barat. Prosiding Seminar Nasional Matematika, Sains, Dan Teknologi, 4, B116-B123. 